\title{
Model Diversifikasi Fungsi Subak sebagai Daya Tarik Ekowisata di Subak Sembung, Peguyangan, Kecamatan Denpasar Utara
}

\author{
I PUTU PUTRA WIGUNA, WAYAN SUDARTA, I KETUT SURYA DIARTA \\ Program Studi Agribisnis, Fakultas Pertanian, Universitas Udayana \\ J1. PB. Sudirman Denpasar 80323 \\ E-mail: ptputrawiguna@gmail.com \\ sudarta_wayan@ymail.com
}

\begin{abstract}
A Model of Subak Diversifying Functions as an Attraction to Ecotourism in Subak Sembung, Peguyangan, North Denpasar
\end{abstract}

Subak Sembung is one of the Subak in Denpasar which has a wide area of farming around 115 Ha. Subak Sembung has becoming an attraction to ecotourism since year of 2014. The Ecotourism in Subak Sembung was established as a water absorption area in Denpasar city. This was meant to keep motivating the farmers not to shift the function of that land. Currently, condition of the field has shown that Subak Sembung is now dealing with a threat of land shifting function because of its existance in the middle of Denpasar city, so the ecotourism in Subak Sembung was then created to further anticipate it. This research discussed about any Subak diversifying functions after the ecotourism in that area was established. It also described the models of its diversification as an attraction in Subak Sembung. The method of analysis used to explain the reseach problem was a descriptive qualitative analysis. That qualitative description was applied on the information received from some key speakers by Krama Subak or the admin of that ecotourism. The results showed that the role and function of Subak brought up to an attranction for Subak Sembung ecotourism. The diversification of those roles and functions included religion ceremony that performed any rituals, therefore Subak could sell a culture in farming. The others were involving facilities operation and maintenance like building a trekking path along the rice field for tourists and also providing other supporting facilities along the area. The establishment of ecotourism was led by Badan Lingkungan Hidup (BLH) and PPLH that had constructed an ecotourism management in 2014. Nevertheless, there was also another issue found regarding with the lack of waste management and abence of share of direct income for the site. Therefore, as a suggestion, a contribution should be given especially to the Subak itself in the future because it would help to motivate the farmers to sustain the rice field area. The farmers should also be open-minded to accept a new innovation, meanwhile both sides of the ecotourism and Subak need to be alert to follow up with the rubbish issue around the area. It is also suggested that Denpasar government in line with the management of ecotourism should give a direct contribution for Subak sustainability in the future.

Key words: subak, ecotourism, functions of Subak, diversification 


\section{Pendahuluan}

\subsection{Latar Belakang}

Subak merupakan salah satu daya tarik wisata di Bali. Subak dapat didefinisikan sebagai lembaga irigasi dan pertanian yang bercorak sosio-religius terutama bergerak dalam pengelolaan air untuk produksi tanaman setahun khususnya padi berdasarkan prinsip Tri Hita Karana (Sutawan, 2008). Ekowisata Subak Sembung merupakan salah satu tempat wisata berbasis lingkungan baru yang ada di tengah Kota Denpasar. Sudarto, 1999 (dalam Arida, 2016) menyatakan bahwa ekowisata adalah kegiatan perjalanan wisata yang bertanggung jawab di daerah yang masih alami atau daerahdaerah yang dikelola dengan keindahan alam tujuannya selain untuk menikmati keindahan juga melibatkan unsur pendidikan, pemahaman, dan dukungan terhadap usaha-usaha konservasi alam dan peningkatan pendapatan masyarakat setempat sekitar daerah tujuan ekowisata. Ekowisata Subak Sembung berlokasi di Kelurahan Peguyangan, Kecamatan Denpasar Utara, Kota Denpasar. Luas daerah Subak Sembung sekitar 115 ha, dengan jumlah anggota sekitar 192 orang. Subak Sembung merupakan salah satu subak yang menjaga kelestarian alam. Subak Sembung masuk kawasan perkotaan di Kota Denpasar yang terus didesak oleh kepentingan pariwisata sehingga rawan alih fungsi lahan. Sampai saat ini karma subak Sembung masih gigih dan patuh terhadap awig-awig mempertahankan sawah. Subak Sembung menjadi harapan kota Denpasar sebagai penjaga kawasan jalur hijau dan menjadi daerah resapan air yang luas. Subak Sembung selain berfungsi sebagai subak yang menjalankan enam fungsi pokok, Subak Sembung juga diproyeksikan sebagai salah satu kawasan ekowisata. Sebagai konteks ekowisata, Subak Sembung mengalami diversifikasi fungsi subak seperti upacara keagamaan, pencarian dan pendistribusian air irigasi, operasi dan pemeliharaan fasilitas, penanganan konflik, mobilitas sumberdaya, dan pengadopsian inovasi sebagai daya tarik ekowisata. Beberapa fungsi dan tugas subak menimbulkan daya tarik ekowisata, maka perlu diteliti diversifikasi fungsi subak sebagai daya tarik ekowisata di Subak Sembung dan proses secara kronologis dijadikannya Subak Sembung sebagai ekowisata dengan memodelkan diversifikasi fungsi subak sebagai daya tarik ekowisata di Subak Sembung itu sangat perlu.

\subsection{Rumusan Masalah}

Berdasarkan latar belakang di atas, dapat dijabarkan rumusan masalah yang diangkat peneliti sebagai berikut.

1. Apa diversifikasi fungsi subak yang menjadi daya tarik ekowisata di Subak Sembung.

2. Bagaimanakah model diversifikasi fungsi subak sebagai daya tarik ekowisata di Subak Sembung. 


\subsection{Tujuan Penelitian}

Berdasarkan rumusan masalah di atas, adapun tujuan dari penelitian ini adalah untuk mengetahui :

1. Diversifikasi fungsi subak yang menjadi daya tarik ekowisata di Subak Sembung.

2. Model diversifikasi fungsi subak sebagai daya tarik ekowisata di Subak Sembung.

\section{Metode Penelitian}

\subsection{Lokasi dan Waktu Penelitian}

Lokasi penelitian dilakukan di Subak Sembung, Peguyangan, Kecamatan Denpasar Utara. Waktu pengumpulan data primer dan data sekunder berlangsung dari bulan Juli sampai bulan Oktober 2017 mulai dari persiapan hingga penyusunan laporan hasil penelitian. Pemilihan lokasi ini dipilih secara sengaja (purposive). Adapun pertimbangan pemilihan lokasi penelitian ini sebagai berikut.

1. Subak Sembung, Kelurahan Peguyangan, Kecamatan Denpasar Utara memiliki permasalahan rawan alih fungsi lahan karena terdesak dengan kepentingan pariwisata, sehingga petani termotivasi untuk mempertahankan lahan sawahnya dengan menjadikannya sebagai daya tarik ekowisata.

2. Krama Subak Sembung, Kelurahan Peguyangan, Kecamatan Denpasar Utara sampai saat ini masih gigih dan patuh terhadap awig-awig.

3. Subak Sembung, Kelurahan Peguyangan, Kecamatan Denpasar Utara merupakan penjaga kawasan jalur hijau dan menjadi daerah resapan air yang luas, sehingga harus dijaga agar tidak terjadi alih fungsi lahan.

\subsection{Sumber dan Jenis Data}

Sumber data dalam penelitian ini meliputi data primer dan data sekunder. Jenis data terdiri atas data kualitatif dan data kuantitatif. Data primer diperoleh dari hasil wawancara mendalam dengan informan kunci menggunakan pedoman wawancara. Informasi langsung dari pekaseh, masing-masing ketua tempek dan pengelola ekowisata. Data sekunder meliputi literatur, artikel, jurmal, situs di internet, gambaran umum daerah penelitian dan kelembagaan Subak Sembung. Data kualitatif menjelaskan mengenai diversifikasi fungsi subak sebagai daya tarik ekowisata di Subak Sembung dan model diversifikasi fungsi subak sebagai daya tarik ekowisata di Subak Sembung. Data kuantitatif berupa jumlah anggota subak, luas areal subak, dan lain-lain.

\subsection{Informan Kunci}

Penentuan informan dalam penelitian kualitatif berfungsi untuk mendapatkan informasi yang maksimum (Sugiyono, 2012), karena itu orang yang dijadikan informan kunci adalah yang memenuhi kriteria sebagai berikut.

1. Mereka menguasai atau memahami sekitar lokasi penelitian 
2. Mereka sedang berkecimpung atau terlibat dalam kegiatan yang berlangsung di lokasi penelitian

3. Mereka mempunyai cukup waktu untuk diwawancarai.

Pemilihan informan dalam penelitian ini menggunakan teknik snowball sampling yaitu teknik pengambilan informan, sumber data, yang pada awalnya berjumlah sedikit, lama-lama menjadi besar. Pemilihan informan dilakukan karena peneliti telah memahami bahwa informasi yang dibutuhkan dapat diperoleh dari suatu kelompok sasaran tertentu yang mampu memberikan informasi yang dikehendaki (Sugiyono, 2009). Pada penelitian ini diambil informan kunci penelitian yaitu : (1) pekaseh Subak Sembung; (2) sekretaris Subak Sembung; (3) pengelola Ekowisata Subak Sembung; (4) kelian Munduk Sembung; (5) sekretaris Ekowisata Subak Sembung; (6) bendahara Subak Sembung; (7) I Gede Ari Bawa; (8) I Wayan Ruja; (9) I Nyoman Tengir, dan (10) I Nyoman Subawa.

\subsection{Pengumpulan Data}

Pengumpulan data dalam penelitian ini melalui observasi, wawancara mendalam, Focus Group Disccusion (FGD), dokumentasi, dan studi kepustakaan. Wawancara mendalam (indepth interview) merupakan proses memperoleh keterangan untuk tujuan penelitian dengan cara tanya jawab dan bertatap muka, dimana informan terlibat dalam kehidupan sosial yang relatif lama (Sutopo, 2006). Wawancara mendalam dilakukan dengan informan kunci yang telah ditentukan dengan menggunakan instrumen penelitian yaitu, pedoman wawancara yang diberikan kepada informan sebanyak empat orang, sedangkan diskusi kelompok terarah atau focus group discussion dihadiri oleh sepuluh orang. Focus group discussion merupakan suatu proses pengumpulan informasi mengenai suatu masalah tertentu yang sangat spesifik (Irwanto, 2007), kegiatan tersebut dilakukan dengan enam orang untuk memvalidasi data dari hasil wawancara mendalam. Observasi dilakukan untuk mengetahui keadaan langsung di Subak Jatiluwih. Dokumentasi dapat berupa foto-foto keadaan wilayah peneltian dan pada saat kegiatan wawancara dengan Informan. Studi kepustakaan dapat diambil dari buku-buku atau internet sebagai tambahan informasi dan data penelitian.

\subsection{Analisis Data}

Penelitian ini menggunakan analisis deskriptif kualitatif yang diperoleh dari hasil observasi, wawancara mendalam, FGD dan dokumentasi. Analisis data dilakukan dengan tiga langkah yakni: pengumpulan data, klasifikasi data dan interpretasi data, dan penarikan kesimpulan akhir (Ibrahim, 2015). Pertama, menghimpun data sebanyak mungkin di lapangan. Kedua, data-data yang telah dikumpulkan kemudian diklasifikasi sesuai dengan tematik atau aspek kajian yang telah ditentukan dalam penelitian ini. Ketiga, pada akhirnya data-data yang sudah diklasifikasi dalam tema/aspek penelitian ditafsirkan dan dimaknai sebagai sebuah kesimpulan akhir dari penelitian ini. 


\section{Gambaran Umum Lokasi Penelitian \\ 3.1 Subak Sembung}

Subak Sembung secara administratif terletak di Desa Peguyangan, Kecamatan Denpasar Utara, Kota Denpasar. Batas-batas wilayah dari subak ini sebagai berikut.

Sebelah Utara

Sebelah Timur

Sebelah Selatan

Sebelah Barat
: Subak Dalem

: Desa Pekraman Peraupan

: Subak Peraupan Barat

: Subak Pakel 1

Subak Sembung memiliki areal persawahan seluas 115 hektar dengan jumlah petani sebanyak 192 orang. Setiap tahunnya Subak Sembung dengan sistem tanam serempak dengan pola tanam padi, palawija sebanyak dua kali musim tanam setiap tahunnya. Sumber air irigasi Subak Sembung berasal dari DAM Tanah Putih.

\subsection{Struktur dan Tugas Organisasi Subak Sembung}

Subak Sembung dipimpin oleh seorang Pekaseh serta dibantu dengan beberapa pengurus lainnya untuk mengkoordinasikan seluruh anggota subak tersebut. Berikut adalah gambar struktur organisasi dari Subak Sembung yang dijelaskan pada gambar 1 .

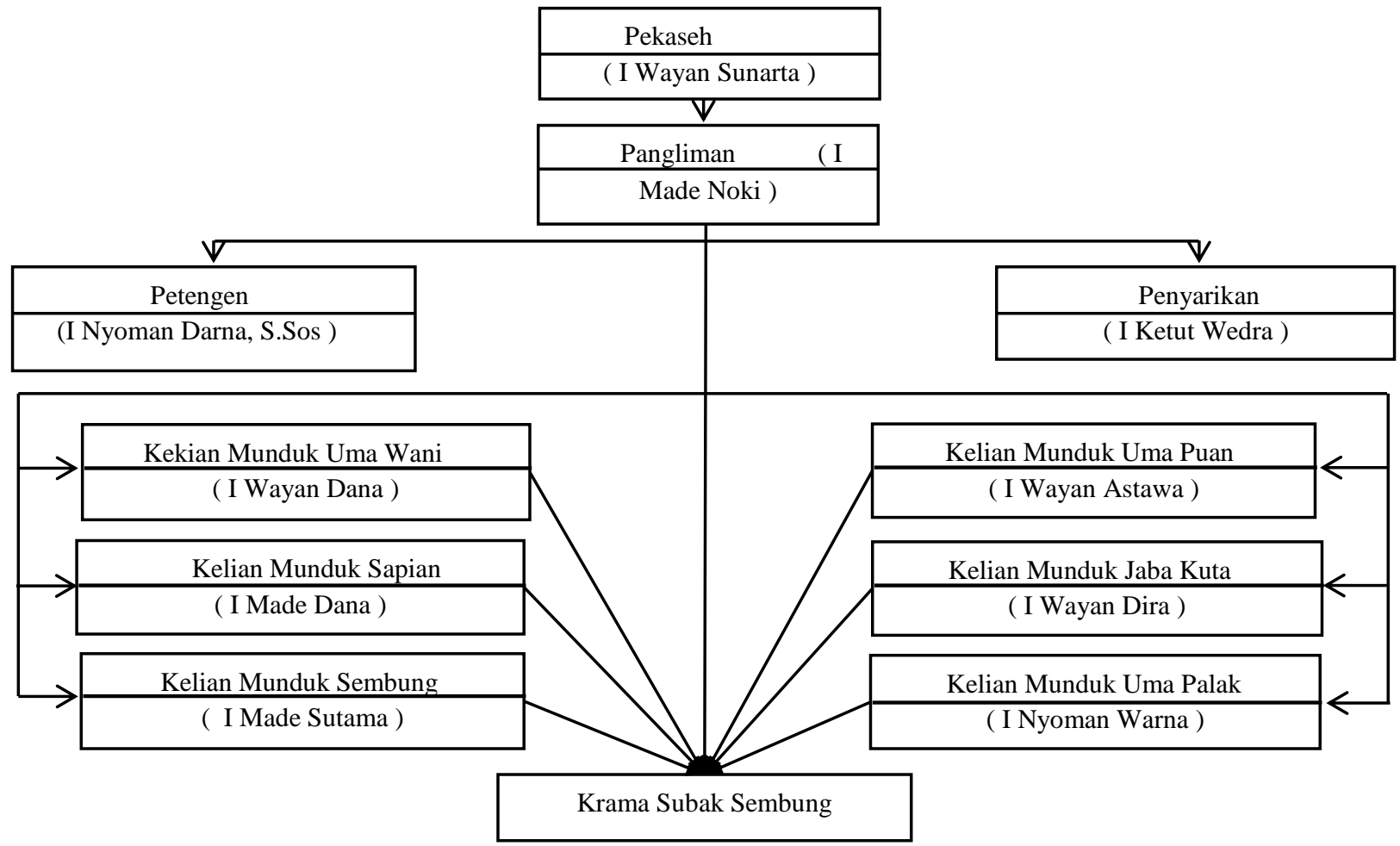

Gambar 1. Struktur Organisasi Subak Sembung

\subsection{Struktur organisasi pengelola ekowisata}

Sejak tahun 2014, ketua dari pengelola ekowisata Subak Sembung dipilih secara aklamasi melalui rapat umum anggota Subak Sembung. Ketua pengelola ekowisata 
diberi hak untuk memilih pengurus yang akan mendampingi dalam menjalankan tugas untuk mengatur kegiatan ekowisata tersebut. Atas dasar kesepakatan bersama dari seluruh anggota Subak Sembung tersebut, pengurus ekowisata tersebut telah dikukuhkan secara resmi melalui surat keputusan (SK) yang dibuat oleh Pekaseh Subak Sembung, kemudian disetujui oleh Kepala Kelurahan Peguyangan dan Kelihan Banjar Pulugambang. Pihak yang menjadi pengurus dari ekowisata tersebut merupakan anggota dari organisasi Subak Sembung. Pengelola ekowisata ini tentunya memiliki struktur kepengurusan yang berbeda dengan struktur kepengurusan dari organisasi Subak Sembung, namun diikat dalam suatu dasar hukum yang sama yakni awig-awig dari Subak Sembung yang bersifat otonom. Hal ini menunjukkan bahwa letak dari pengelola ekowisata adalah diluar dari kepengurusan Subak Sembung, yang dimana pengurus ekowisata ini berperan dalam mengelola kegiatan ekowisata serta menunjang kegiatan usahatani di Subak Sembung guna mengembangkan kawasan ekowisata tersebut. Struktur organiasi dari pengelola ekowisata Subak Sembung yang dijelaskan pada gambar 2.

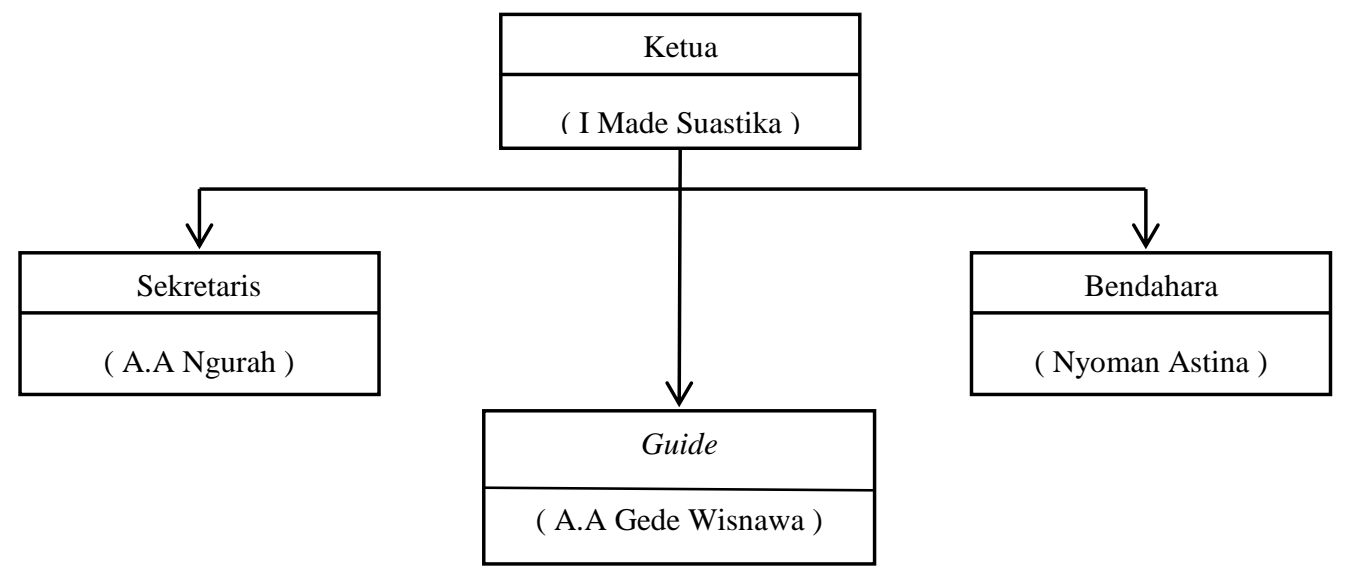

Gambar 2. Struktur Organisasi Pengelola Ekowisata Subak Sembung

\section{$4 \quad$ Hasil dan Pembahasan}

\subsection{Diversifikasi Fungsi Subak yang Menjadi Daya Tarik Ekowisata di Subak Sembung}

Sesuai dengan data empiris dilapangan bahasa ekowisata Subak Sembung merupakan pelestarian areal subak. Diversifikasi fungsi subak yang menjadi daya tarik ekowisata setelah adanya ekowisata Subak Sembung adalah pada kegiatan upacara keagamaan. Kegiatan upacara keagamaan menimbulkan daya tarik ekowisata karena mempertontonkan kegiatan upacara keagamaan, sehingga subak menjual kebudayaan pertanian dengan mempertontonkan kegiatan upacara keagamaan yang dilakukan di areal persawahan. Daya tarik yang ditimbulkan pada pelaksanaan kegiatan upacara keagamaan, yaitu dalam penggunaan sarana dan prasarana seperti saat melakukan upacara mapag toya merupakan suatu upacara menjemput air kesumber air. Kegiatan upacara ini dilaksanakan secara individu yang bertujuan untuk memohon kepada Tuhan dalam manifestasinya sebagai Dewa Air (Dewa Baruna) agar subak tidak sampai 
kehilangan air atau kekurangan air dan upacara dewa nini yang dilakukan pada saat menjelang panen. Dua hari menjelang panen, petani membuat dewa nini sebagai lambang Dewi Sri dengan mempergunakan beberapa helai tangkai padi, setelah upacara dewa nini dilaksanakan maka petani boleh memetik padi atau panen. (Sumadi, 2015).

Pencarian dan distribusi air irigasi tidak menimbulkan daya tarik ekowisata, dan tidak ada diversifikasi fungsi subak karena hanya menerapkan fungsi pokok subak. Operasi dan pemeliharaan fasilitas irigasi menjadi daya tarik ekowisata karena masih adanya kegiatan tradisional seperti gotong-royong, melestarikan membajak sawah dengan sapi, pinjaman air irigasi serta hal tersebut merupakan implementasi dari Tri Hita Karana (THK) dalam bentuk pawongan. Diversifikasi fungsi subak yang terjadi, dijadikannya jalur usaha tani sebagai jalur tracking untuk wisatawan, adanya tempat jualan untuk ibu tani di sepanjang jalur tracking, adanya balai bengong dan bangku beton di areal subak, serta penggunaan areal subak sebagai tempat lomba-lomba seperti lomba menanam padi, lomba ngejuk bebek, lomba menangkap belut, lomba layanglayang dan lomba membajak sawah.

Penanganan konflik tidak menimbulkan daya tarik ekowisata karena tidak terjadi diversifikasi tugas dan fungsi subak, fungsi subak semula tetap hanya penanganan konflik secara internal subak saja. Mobilitas sumber daya tidak menimbulkan daya tarik ekowisata, karena hanya menjalankan fungsi utama subak yaitu pengerahan sumberdaya, baik sumberdaya modal, uang, material, tenaga kerja atau yang lain, untuk membantu mewujudkan terlaksananya kegiatan pendistribusian air irigasi, pemeliharaan fasilitas subak, dan pelaksanaan upacara keagamaan.

Pengadopsian inovasi menimbulkan daya tarik ekowisata di Subak Sembung dengan pengadopsian inovasi berupa penataan jalur usaha tani dimana sistem subak sebelumnya belum menata jalur usaha tani sehingga dengan pemavingan jalur usaha tani dapat menimbulkan daya tarik ekowisata dan terjadi diversifikasi dalam pengadopsian inovasi subak, selain itu pengadaan balai bengong dan bangku beton juga menimbulkan daya tarik ekowisata. Adanya pengadopsian inovasi modern, tidak menghilangkan fasilitas tradisional seperti gubuk bambu yang menjadi tempat istirahat petani dan sampai saat ini tetap tersedia di areal subak. Fasilitas penunjang lainnya juga mendukung ekowisata seperti pembajakan sawah yang bisa dilakukan langsung oleh wisatawan di petakan sawah petani. Pembajakan sawah juga masih menerapkan pembajakan dengan sapi, serta pembajakan modernpun ada sehingga wisatawan bisa menerapkan langsung proses pembajakan sawah tersebut serta dengan pengadopsian inovasi menimbulkan diversifikasi fungsi subak dimana fungsi subak semula hanya menerapkan sistem tradisional dan sekarang sudah menerapkan sistem modern tanpa menghilangkan sistem tradisional.

\subsection{Model Diversifikasi Fungsi Subak Sebagai Daya Tarik Ekowisata di Subak Sembung}

Model yang dimaksud dalam diversifikasi fungsi subak sebagai daya tarik ekowisata di Subak Sembung merupakan proses kronologis terjadinya Ekowisata Subak 
Sembung atau bagaimana tahapan dijadikannya Subak Sembung sebagai ekowisata. Awal dijadikannya Subak Sembung sebagai daya tarik ekowisata karena Subak Sembung merupakan salah satu subak yang lestari di daerah perkotaan Denpasar. Badan Lingkungan Hidup (BLH) Denpasar bekerjasama dengan Pusat Pendidikan Lingkungan Hidup (PPLH) membentuk Ekowisata Subak Sembung yang bertujuan agar petani Ekowisata Subak Sembung tidak melakukan alih fungsi lahan, dan memotifasi petani dengan cara pengadaan peken carik, serta penjualan hasil pertanian langsung di areal sawah. Pengelola ekowisata juga dibentuk oleh Pemkab pada tahun 2014, tetapi dengan dijadikannya ekowisata Subak Sembung hanya meningkatkan pendapatan beberapa individu petani. Kegiatan tersebut nlm memenuhi prinsip ekowisata pendapatan langsung untuk kawasan, mengatur agar kawasan yang digunakan untuk ekowisata dan manajemen pengelola kawasan pelestarian dapat menerima langsung penghasilan atau pendapatan, retribusi dan conservation tax dapat dipergunakan secara langsung untuk membina, melestarikan dan meningkatkan kualitas kawasan pelestarian alam. Perlu dilakukan kegiatan yang memberikan pemasukan ke subak, agar nantinya subak termotivasi untuk mempertahankan lahan mereka.

\section{Simpulan dan Saran \\ 5.1 Simpulan}

Berdasarkan hasil dan penelitian di atas yang telah dijelaskan dan dipaparkan sesuai dengan rumusan masalah yang telah dilakukan maka dapat disimpulkan beberapa hal pokok sebagai berikut.

1. Diversifikasi fungsi subak yang menjadi daya tarik ekowisata di Subak Sembung, sebagai berikut.

a) Kegiatan upacara keagamaan

Kegiatan upacara keagamaan menimbulkan daya tarik ekowisata karena merupakan implementasi dari Tri Hita Karana (THK), diversifikasi kegiatan upacara keagamaan selain untuk permohonan kemakmuran dalam kegiatan pertanian, upacara keagamaan tersebut juga dipertontonkan kepada wisatawan, sehingga subak menjual kebudayaan pertanian dengan mempertontonkan kegiatan upacara keagamaan yang dilakukan di areal persawahan.

b) Operasi dan pemeliharaan fasilitas

Operasi dan pemeliharaan fasilitas irigasi menjadi daya tarik ekowisata karena masih adanya kegiatan tradisional seperti gotong-royong, melestarikan membajak sawah dengan sapi, pinjaman air irigasi serta hal tersebut merupakan implementasi dari Tri Hita Karana (THK) dalam bentuk pawongan. Diversifikasi fungsi subak yang terjadi, dijadikannya jalur usaha tani sebagai jalur tracking untuk wisatawan, adanya tempat jualan untuk ibu tani di sepanjang jalur tracking, adanya balai bengong dan bangku beton di areal subak, serta penggunaan areal subak sebagai tempat 
lomba-lomba seperti lomba menanam padi, lomba ngejuk (menangkap) bebek, dan lomba membajak sawah.

c) Pengadopsian inovasi

Pengadopsian inovasi menimbulkan daya tarik ekowisata di Subak Sembung dengan pengadopsian inovasi berupa pembuatan jalur usaha tani, pengadaan balai bengong dan bangku beton serta fasilitas penunjang lainnya yang mendukung ekowisata serta dengan pengadopsian inovasi menimbulkan diversifikasi fungsi subak dimana fungsi subak semula hanya menerapkan sistem tradisional dan sekarang sudah menerapkan sistem modern tanpa menghilangkan sistem tradisional.

2. Model yang dimaksud dalam diversifikasi fungsi subak sebagai daya tarik ekowisata di Subak Sembung merupakan proses kronologis terjadinya Ekowisata Subak Sembung atau bagaimana tahapan dijadikannya Subak Sembung sebagai ekowisata, berawal sejak Agustus 2014 Badan Lingkungan Hidup (BLH) Denpasar bekerja sama dengan Pusat Pendidikan Lingkungan Hidup (PPLH) untuk mendirikan Ekowisata Subak Sembung, melalui kegiatan lomba-lomba dan pembinaan-pembinaan untuk proses pendekatan agar krama subak bisa menerima bahwa subak sembung dijadikan ekowisata. Krama subak menyetujui dibentuknya pengurus ekowisata pada tanggal 27 September 2014 dengan masa jabatan tiga tahun. Tujuan pemerintah Kota Denpasar mendirikan ekowisata untuk memotivasi petani Subak Sembung agar tidak melakukan alih fungsi lahan karena Kota Denpasar rawan alih fungsi lahan. Salah satu acara memotivasi petani subak sembung dengan cara menjual hasil pertanian di areal sawah dan pengadaan peken carik setiap hari sabtu dan minggu. Tujuan kegiatan tersebut untuk meningkatkan pendapatan perindividu petani.

\subsection{Saran}

Terdapat beberapa kegiatan yang menimbulkan daya tarik ekowisata di Subak Sembung, permasalahan yang perlu diantisipasi dengan tindakan-tindakan seperti yang direkomendasikan di bawah ini.

1) Pihak Subak, perlu melakukan kegiatan yang menimbulkan daya tarik ekowisata pada fungsi subak pendistribusian air irigasi dengan cara pengadaan lomba memancing di saluran irigasi sehingga fungsi subak pendistribusian air irigasi mengalami diversifikasi selain sebagai penyalur air irigasi petani juga dapat digunakan sebagai tempat lomba memancing ikan, sehingga menimbulkan daya tarik ekowisata.

2) Pihak Ekowisata dan Subak, dengan adanya permasalahan sampah di Ekowisata Subak Sembung perlu dilakukan kegiatan tindak lanjut dari sampah yang ada di sekitar areal subak, karena menganggu saluran irigasi subak. Hal yang dapat dilakukan seperti kegiatan pengangkutan sampah secara bergilir dari masingmasing munduk yang ada di Subak Sembung setiap seminggu atau dua minggu sekali, agar lestarinya lingkungan subak. 
3) Pemerintah Kota Denpasar, dari permasalahan ancaman alih fungsi lahan maka dibentuknya ekowisata di Subak Sembung. Pihak pemerintah harus tetap mendukung petani dengan cara mengadakan kegiatan atau lomba-lomba yang diadakan di Ekowisata Subak Sembung sehingga petani lebih semangat mengikuti kegiatan yang diadakan pemerintah sehingga dari kegiatan yang diadakan tersebut dapat memotivasi petani untuk tetap mempertahankan lahannya agar tidak melakukan alih fungsi lahan.

\section{Ucapan Terimakasih}

Terimakasih kepada semua pihak yang telah memberikan bantuan berupa data, buah fikiran, ke bendaan dan lain-lain sehingga e-jurnal ini dapat diselesaikan dengan baik. Semoga hal didalamnya bermanfaat adanya.

\section{Daftar Pustaka}

Arida Sukma, Nyoman. 2016. Dinamika Ekowisata Tri Ning Tri di Bali. Denpasar: Pustaka Larasan

Desa Peguyangan. 2015. Profil dan Potensi Desa Peguyangan. Tidak diterbitkan: Denpasar.

Ibrahim, M. A. 2015. Metodelogi Penelitian Kualitatif. Alfabeta, Bandung.

Irwanto. 2007. Focus Group Discussion: Sebuah Pengantar Praktis. Jakarta: Yayasan Obor Indonesia.

Subak Sembung. 2014. Eka Ilikita Subak Sembung Desa Peguyangam. Tidak diterbitkan: Denpasar.

Sugiyono. 2009. Penelitian Kualitatif. Alfabeta, Bandung.

Sugiyono. 2012. Memahami Penelitian Kualitatif. Alfabeta, Bandung.

Sumadi, Suca Wayan dkk. 2015. Upacara Pertanian dalam Sistem Subak Di Bali. Yogjakarta: Kepel Press

Sutawan, Nyoman. 2008. Organisasi dan Manajemen Subak di Bali. Denpasar: Pustaka Bali Post

Sutopo, HB. 2006. Metode Penelitian Kualitati. Surakarta: UNS Press. 